\title{
Chronological versus dental age in subjects from 5 to 19 years: a comparative study with forensic implications
}

\author{
Claudia Corral ${ }^{1}$, Felipe García ${ }^{1}$, Jorge García ${ }^{1}$, Pilar León ${ }^{1}$, Adriana Herrera, OD², \\ Carlos Martínez, OD ${ }^{3}$, Freddy Moreno, OD ${ }^{4}$
}

\section{SUMMARY}

Objectives: This study evaluated six methods used in estimating the age of patients attending the Dental School at Universidad del Valle, evaluating dental development by using panoramic radiographs. Additionally, the study determined the sexual identity of the person and the bilateral symmetry of development, the maturity and the chronological eruption of permanent teeth.

Materials and methods: This is a descriptive, quantitative and transversal study that evaluated which of the six methods (Logan \& Kronfeld; Schour \& Massler; Moorrees, Fanning \& Hunt; Demirjian, Goldstein \& Tanner; Ubelaker \& Smith) for estimating the age of a patient through radiographic evaluation of dental development is the most correlated with the chronological age of the patient, so it can be used for forensic purposes.

Results: The Moorrees, Fanning \& Hunt and the Smith methods showed high correlation ( 0.7874 and 0.7808 , respectively). The Logan \& Kronfeld methods presented low correlation (0.6879). The sample studied did not show sexual dimorphism or bilateral asymmetry.

Conclusions: All methods evaluated have a high correlation coefficient between the dental age and the radiographic age. However, the Moorrees, Fanning \& Hunt, and Smith methods presented higher correlation coefficients between dental and chronological age.

Keywords: Forensic sciences; Forensic dentistry; Dental age.

Edad cronológica vs. edad dental en individuos de 5 a 19 años: un estudio comparativo con implicaciones forenses

\section{RESUMEN}

Objetivos: Se evaluaron seis métodos para calcular la edad a partir del desarrollo dental mediante radiografías panorámicas en pacientes de la Escuela de Odontología de la Universidad del Valle respecto a la edad cronológica. Se determinaron también el dimorfismo sexual y la simetría bilateral del desarrollo, maduración y erupción de los dientes permanentes.

Materiales y métodos: Estudio descriptivo transversal cuantitativo que evaluó la concordancia entre seis métodos para estimar la edad a partir del desarrollo dental (Logan y Kronfeld; Schour y Massler; Moorrees, Fanning y Hunt; Demirjian, Goldstein y Tanner; Ubelaker y Smith) y la edad cronológica a partir de las radiografías panorámicas, con fines forenses.

Resultados: Los métodos de Moorrees, Fanning y Hunt y de Smith presentan una mayor correlación (0.7874 y 0.7808 respectivamente). Asimismo, el método de Logan y Kronfeld es el que presenta la correlación menor (0.6879). La muestra estudiada no presentó ni dimorfismo sexual ni asimetría bilateral.

Conclusiones: Todos los métodos tenidos en cuenta en este estudio resultan adecuados para calcular la edad de un individuo, sin embargo los métodos de Moorrees, Fanning y Hunt y de Smith presentaron los mayores coeficientes de correlación entre la edad dental y la edad cronológica.

Palabras clave: Ciencias forenses; Odontología forense; Edad dental.

1. Dentistry students, School of Dentistry, Universidad del Valle, Cali, Colombia. e-mail: clauco18@hotmail.com felipe44_4@hotmail.com kuiki911@hotmail.com pilejava24@hotmail.com

2. Professor, School of Dentistry, Universidad del Valle, Cali,Colombia.e-mail: adrianaherrera65@ hotmail.com

3. Professor, School of Dentistry, Universidad del Valle, Researcher Oral and Maxillofacial Surgery Group, Universidad del Valle, Cali, Colombia.e-mail: carlosbettin@ hotmail.com

4. Professor, School of Dentistry, Universidad del Valle. Researcher Oral and Maxillofacial Surgery Group, Universidad del Valle,Cali,Colombia.e-mail:freddymg@univalle.edu.co

Received for publication March 5, 2009 Accepted for publication February 9, 2010 
Identifying humans has become a fundamental backbone of civilization because societies demand the establishment of the identity of individuals, alive or after their death, with the objective of alleviating the sorrow of their close ones with social, legal, political, and economic purposes. During the identification process of an individual's remains, cadaver, or a live person, we must fill out what is known within the anthropological and forensic context as the basic identification quatrain (which includes obtaining an age estimation, as well as the determination of gender, ethnicity, and height), which will allow knowing the identity of an individual through the analysis of osseous structures and dental characteristics ${ }^{1}$.

The estimation of an individual's age consists of the study of osseous and dental characteristics to have a close approximation of a human being's chronological age. The analysis of these processes is based on the determination and quantification of the events occurring during the growth and development processes, given that they generally present a constant sequence, as a result of a genetic-environmental interrelation that determines that in the general population some individuals will have different maturity rhythms ${ }^{1}$.

In specialized literature, there are different methods studying the development, maturity and tooth eruption for the purpose of estimating biological age from the teeth and managing an approximation to the chronological age; bearing in mind that the tendencies in the proportions of dental maturation vary with respect to the ethnic group studied and that these even vary among members of a same ethnic group, depending on the geographic distribution and environment. These methods are supported based on the evidence presented by the fact that the development and formation of the teeth is produced slowly and constantly along a period of time between the fetal stage until reaching 20 years of age and on the degenerative changes of the dental tissue occurring from that moment, in such a manner that we could eventually estimate age from an interval of the biological age to approximate the chronological age ${ }^{2}$.

In Colombia few studies have been conducted in this field. In 2001, Arévalo and Infante ${ }^{3}$ compared four radiographic methods to determine dental age from permanent teeth in a sample of mestizos from Bogotá, concluding that the methods by Smith and Moorrees reached a greater degree of correspondence between age of dental maturation and chronological age; Hernández and Sierra ${ }^{4}$ analyzed different dental and osseous structures that could determine biological age and characterize three legally important chronological age groups; thereby, developing a suitable and applicable model for the Colombian population and which is currently employed by the National Institute for Legal Medicine and Forensic Sciences in Bogotá (Instituto Nacional de Medicina Legal y Ciencias Forenses, Seccional Bogotá). Likewise, this study determined that dental maturation was more effective than osseous maturation through the carpogram when estimating biological age.

Thus, through this analysis of dental development we can obtain valuable information from deceased humans in a way which facilitates identifying an individual and provides preliminary forensic proof that can guide judicial proceedings. For living individuals, the opinion of age within the of forensic sciences, especially forensic dentistry, plays an important judicial role due to the classification of a crime that may have been committed by a juvenile who is less than 14 years of age or who is between 14 and 18 years of age, which will determine how they will be penalized, the place of reclusion, and restoration of rights: under legal age per the Code for Children and Adolescents (Legislation 906 of 2004) and of legal age per the Penal Code (Legislation 1098 of 2006). Similarly, in cases of victimizers, these will be aggravated if the victims are less than 14 years of age.

However, there are difficulties when estimating the biological age of an individual with forensic purposes, for this reason macroscopic methods have been devised for chronological age approximation based on osseous development (observation of the shape and state of metamorphosis of the ossification centers, epiphyseal closure, and length of some bones), growth and development of hair on the body and external sexual organs, and development stages, along with dental erruption $^{2,5}$. Hence, in view of the great quantity of methods available in specialized literature around the world and the scant research in Colombian populations, this study seeks to evaluate which method is best suited in estimating age from dental development through panoramic radiographs in patients attending the School of Dentistry at Universidad del Valle.

Age estimation. The concept of biological or physiological age is based on the degree of an individual's morphological and functional differentiation through one 
or more tissue systems, whenever said differences are given by the sequence of multiple irreversible events, which are observed via clinical exploration and radiographic analysis ${ }^{6}$. Legal and forensic circles talk about: chronological age or real age when bearing in mind the passage of time in years, months, and days without counting the intrauterine period; of documental age obtained from documents like the certificate of live birth, the birth certificate, the citizen' sidentification, and the passport among others ${ }^{4,5}$; and, finally, of the dental age, which is determined based on the development stages of temporary and permanent dentitions and the physiological degenerative phenomena occurring throughout the individual's lifetime like wear through attrition, obliteration of the pulp chamber, and dentinal sclerosis among others ${ }^{1,7,8}$.

Methods for age estimation. The methods mostly used and applied within forensic sciences to estímate age in human remains are those involved in macroscopic and radiographic manner of the description of the state of maturation or development of the bones and/or teeth. Nevertheless, the teeth constitute a very reliable source in age estimation because the enamel is the hardest tissue in the human organism and has a high capacity for taphonomic preservation even under extreme conditions of $\mathrm{pH}$, humidity, salinity, and high temperatures ${ }^{1,9,10}$; in addition to the nature of the dentine, which is isolated from the environment and is very stable and grants the teeth the capacity to present low susceptibility to big changes related to external stimuli, in such a way that the formation and resorption processes of the dentine are very low in relation to the bone ${ }^{1}$. Similarly, for age estimation based on maturation, the teeth are more convenient structures given that they are less affected by endocrine disease, dietary deficiency states, and environmental aspects affecting their development, providing their total mineralization and erruption occurr within the oral cavity $3,11,12$.

Dental development and maturation. The process of dental maturation is correlated to different mineralization morphological stages that can be radiographically observed and whose process follows a much more uniform, progressive, sequenced, and continuous than the eruption, and less influenced upon by external factors. For these reasons, diverse age estimation methods have been developed based on the mineralization stage of tooth germs. All the age evaluation methods based on dental maturation follow the same systematic approach in which estimating age merely implies having oral radiographies, which can be used in live subjects, cadavers, and skeletal remains ${ }^{1}$.

\section{MATERIALS AND METHODS}

Type of study. This is a quantitative transversal descriptive study, which seeks to evaluate six methods to estimate chronological age from dental development through panoramic radiographs in patients attending the School of Dentistry at Universidad del Valle. Additionally, this work will determine the sexual dimorphism and bilateral symmetry of dental development and maturation.

Population and sample. To make up the sample, we reviewed the inactive file clinical charts from the School of Dentistry at Universidad del Valle and kept in mind 196 panoramic radiographs conveniently selected from Colombian individuals from both genders (109 women and 87 men), between 5 and 19 years of age without dental syndromes and malformations affecting development, maturation, and number of teeth. Likewise, the clinical histories needed to have the date of birth of the individual and the date the radiographs were taken to arrive at the patient's chronological age. It should be mentioned that the chronological age was converted to decimal age to permit correlating it to age estimated by the different methods.

Standarization of the study. Observers received training by an expert in oral and maxillofacial radiology diagnosis, who taught the systematic method of observation of a panoramic radiograph and the radiographic methods reported most in specialized literature (Logan and Kronfeld; Schour and Massler; Moorrees, Fanning and Hunt; Demirjian, Goldstein and Tanner; Ubelaker and Smith) to estimate age from the development of the teeth.

Observation. Once the research is endorsed by the Human Ethics Committee of the Faculty of Health at Universidad del Valle and according to ethical principles for medical research on human beings indicated by the World Medical Association in the Helsinki Declaration; we proceeded to conduct the observation, analysis, and tabulation of the 196 panoramic radiographs through the six methods kept in mind in this study with the aid of a viewbox and a 10X clamp magnifier. The X-ray signs were kept hidden to keep the observers from knowing 
Table 1

Correlation of age estimation methods with radiographic chronological age

\begin{tabular}{lccccccc}
\hline & Age Rx & LK & SM & MFH & DGT & U & S \\
\hline Methods & 1.0000 & & & & & & \\
LK & 0.6879 & 1.0000 & & & & & \\
SM & 0.7746 & 0.8390 & 1.0000 & & & & \\
MFH & 0.7874 & 0.7977 & 0.8877 & 1.0000 & & & \\
DGT & 0.7758 & 0.8026 & 0.8748 & 0.9270 & 1.0000 & & \\
U & 0.7712 & 0.7889 & 0.8874 & 0.9154 & 0.9026 & 1.0000 & \\
S & 0.7808 & 0.7568 & 0.8515 & 0.9313 & 0.9111 & 0.8943 & 1.0000 \\
\hline
\end{tabular}

Age Rx (chronological age), LK (Logan and Kronfeld), SM (Schour and Massler), MFH (Moorrees, Fanning and Hunt), DGT (Demirjian, Goldstein and Tanner), U (Ubelaker) and S (Smith)

the chronological age of the individual and, thus, reduce bias.

Statistical analysis. Upon registering the observation results on an Excel® spreadsheet, we proceeded to determine the degree of correlation among the age of dental maturation and chronological age with each of the methods, sexual dimorphism, and bilateral asymmetry through the Stata software version 10 via the Spearman nonparametric correlation test. Additionally, BlandAltman plots were drawn to evidence agreement between age estimation via any of the methods and chronological age via MedCalc. The variables kept in mind were radiographic chronological age, dental age, gender, bilateral asymmetry, age estimation methods used, and dental maturation stages.

\section{RESULTS}

The Moorrees, Fanning and Hunt, and Smith methods represent greater correlation with respect to chronological age. The Logan and Kronfeld method presented the lowest correlation (Table 1).

The agreement of the six methods was plotted (Bland and Altman agreement plot) to show the average ratios between chronological age and estimated age by using each method, i.e., if the chronological age is greater than that estimated by the method (the ratio is greater than 1), then the calculated dental age was underestimated; conversely, if the chronological age is lower than that estimated by the method (the ratio was less than 1), indicating the calculated dental age was overestimated. On the graphics, the $\mathrm{X}$ axis shows the average ages and the $Y$ axis shows the ratio between the chronological age and the dental age estimated by each method.

The blue line corresponds to the average of the ratios; the red dotted line represents the null value (based on this line the agreement of the method is determined, if this line agrees with the agrees with the blue line it indicates absolute agreement), the blue solid line indicates the average of ratios of radiographic age over the age estimated by each method, and the dotted burgundy lines mark off the standard deviations indicating the best agreement.

Based on this, the methods by Logan and Kronfel, Schour and Masler, Moorrees, Fanning and Hunt, Ubelaker, and Smith tended to overestimate age with respect to radiographic age (Graphics 1,2,3,5,6), while the method by Dermijian, Goldstein and Tanner underestimated age (Graphic 4).

With respect to sexual dimorphism, none of the six methods showed differences in the correlation of estimated age and radiographic age between men and women. Nevertheless, there is a tendency among men for revealing higher correlation coefficients. Likewise, the Logan and Kronfeld method presented the lowest correlation levels in both sexes.

Regarding bilateralism, big differences were not observed in dental development between the right and left sides, which present a strong correlation with respect to radiographic age and among such (Table 2). 


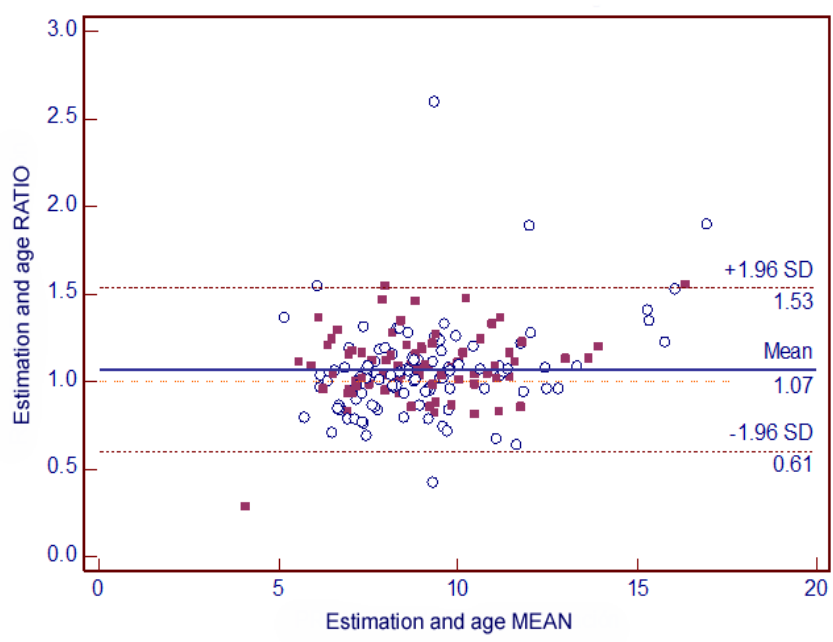

Graphic 1. Agreement between the Logan and Kronfeld method and chronological age (Males: squares, Females: circles)

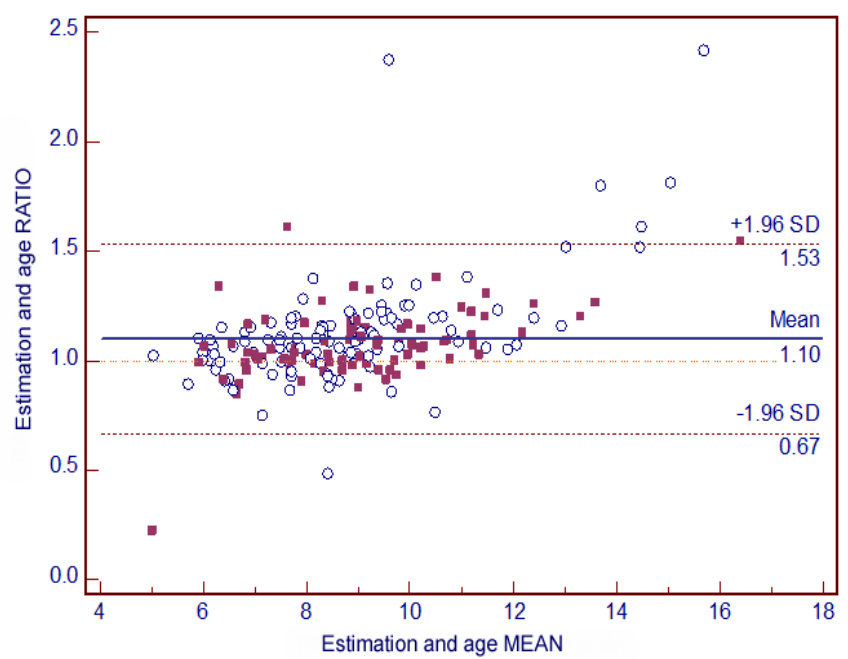

Graphic 3. Agreement between the Moorrees, Fanning and Hunt method and chronological age (Males: squares, Females: circles)

\section{DISCUSSION}

Logan \& Kronfeld (1933). In 1933, these authors discovered calcification age, complete formation age, eruption age, and exfoliation age of each of the teeth from 25 dissected post-mortem specimens with ages between zero months to 15 years. The margin of error was estimated as \pm 1.5 years without regard to gender. The Logan and Kronfeld method is a graphic comparative method of the dental eruption and development process. It was the first study of this type reported used for clinical dentistry purposes. In this study, the Logan and

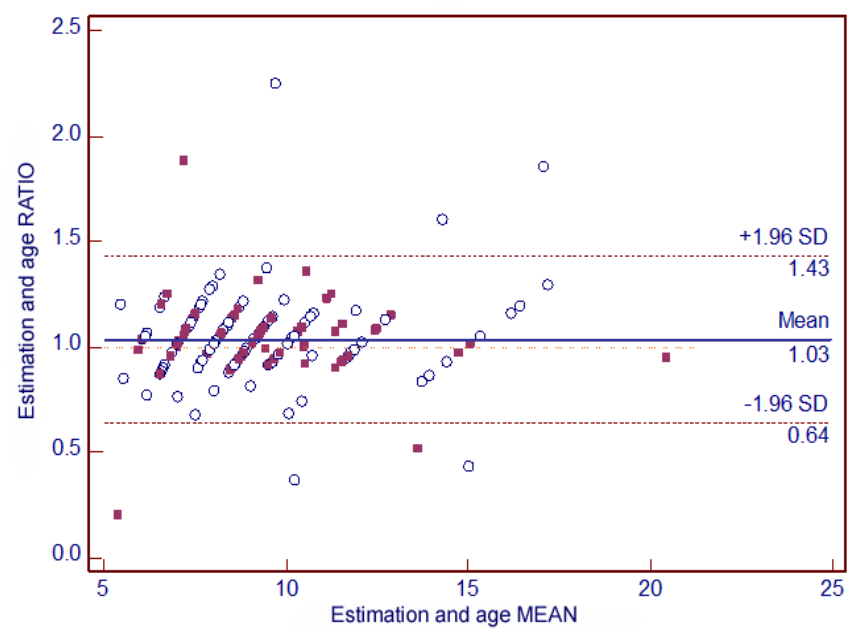

Graphic 2. Agreement between the Schour and Massler method and chronological age (Males: squares, Females: circles)

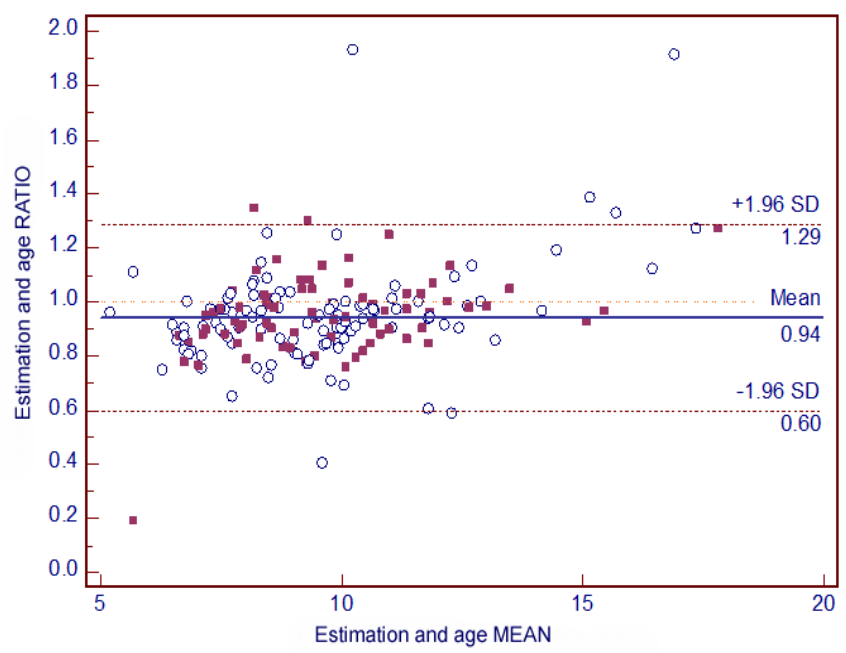

Graphic 4. Agreement between the Dermijian, Goldstein and Tanner method and chronological age (Males: squares, Females: circles)

Kronfeld method presented the lowest correlation coefficient between dental age and chronological age, with a tendency to overestimating the chronological age $^{13}$.

Schour \& Massler (1941). This method, based on the Logan and Kronfeld method, consists of comparing the development stage of the teeth through a panoramic radiograph with a map of images representing the temporary and permanent dentition development phases. The limitation of this method lies in the sample size, which does not estimate sexual dimorphism and that the age ratio was estimated as \pm 6 months, which is a very 
Table 2

Correlation of age estimation methods with radiographic chronological age with respect to bilateralism

\begin{tabular}{|c|c|c|c|c|c|c|c|c|c|c|c|c|c|}
\hline & Age $R x$ & LKr & LKI & SMr & SMI & MFHr & MFHI & DGTr & DGTI & Ur & UI & Sr & UI \\
\hline Age $R x$ & 1.0000 & & & & & & & & & & & & \\
\hline LKr & 0.6879 & 1.0000 & & & & & & & & & & & \\
\hline LKI & 0.6879 & 1.0000 & 1.0000 & & & & & & & & & & \\
\hline SMr & 0.7741 & 0.8410 & 0.8410 & 1.0000 & & & & & & & & & \\
\hline SMI & 0.7739 & 0.8378 & 0.8378 & 0.9986 & 1.0000 & & & & & & & & \\
\hline MFHr & 0.7841 & 0.7930 & 0.7930 & 0.8795 & 0.8822 & 1.0000 & & & & & & & \\
\hline MFHI & 0.7842 & 0.7959 & 0.7959 & 0.8845 & 0.8869 & 0.9819 & 1.0000 & & & & & & \\
\hline DGTr & 0.7746 & 0.8020 & 0.8020 & 0.8727 & 0.8759 & 0.9283 & 0.9178 & 1.0000 & & & & & \\
\hline DGTI & 0.7767 & 0.8031 & 0.8031 & 0.8728 & 0.8759 & 0.9269 & 0.9178 & 0.9992 & 1.0000 & & & & \\
\hline Ur & 0.7589 & 0.7859 & 0.7859 & 0.8778 & 0.8788 & 0.9051 & 0.9012 & 0.8949 & 0.8936 & 1.0000 & & & \\
\hline UI & 0.7691 & 0.7828 & 0.7828 & 0.8793 & 0.8794 & 0.9018 & 0.9017 & 0.8966 & 0.8950 & 0.9677 & 1.0000 & & \\
\hline $\mathrm{Sr}$ & 0.7699 & 0.7607 & 0.7607 & 0.8490 & 0.8516 & 0.9279 & 0.9252 & 0.9143 & 0.9140 & 0.8942 & 0.8955 & 1.0000 & \\
\hline SI & 0.7831 & 0.7355 & 0.7355 & 0.8329 & 0.8358 & 0.9065 & 0.9109 & 0.8917 & 0.8914 & 0.8569 & 0.8631 & 0.9636 & 1.0000 \\
\hline
\end{tabular}

Age Rx (radiographic age), LK (Logan and Kronfeld), SM (Schour and Massler), MFH (Moorrees, Fanning and Hunt), DGT (Demirjian, Goldstein and Tanner), U (Ubelaker), S (Smith), r (right), I (left).

tight range. This is a comparative graphic method, which graphically represents in Atlas manner 21 different chronological stages of dental maturation and eruption ${ }^{14}$. In 2005, H. M. Liversidge conducted a comparison of five methods (Schour and Massler, Gustafson and Koch, Moorrees, Fanning and Hunt, Smith, and Deutsch, Tam and Stack) to estimate ages in 63 individuals between 0 and 5.4 years, concluding that the graphic method by Schour and Massler was considerably more exact than the methods based on the mineralization of the stages of teeth formation, in addition to being easily applied and interpreted ${ }^{15}$. In this study, the correlation coefficient for the Schour and Massler method was high and overestimated the chronological age.

Moorrees, Fanning \& Hunt (1963). For estimating dental age, mandibular teeth are generally used because the overlapping of osseous structures hinders analysis of maxillary teeth. The values of ages corresponding to the formation stages are averaged obtaining the dental age through the mean. This is a graphic (14 stages of dental development evidencing three great stages of dental development: crown formation, reticular formation, and apical closure) and quantitative numerical method that performs very well in individuals from 4.7 to 20.7 years of age ${ }^{16}$. This method, whose results applied to Canadian populations yield a standard deviation of \pm 0.56 years for only one tooth and \pm 0.09 years when five or more teeth are averaged, indicating that the age of a young person can be estimated with a margin of error close to two months ${ }^{2}$. In this study, the method by Moorrees, Fanning and Hunt presented the highest correlation coefficient between dental age and radiographic age (Table 1) with a tendency to overestimating the radiographic age (Graphic 3).

Demirjian, Goldstein \& Tanner (1973). This is currently the most used method for chronological age estimation stemming from dental maturation. In 1976, Demirjian, Goldstein and Tanner evaluated radiographically the degree of mineralization of the seven teeth of the mandibular left quadrant. The method establishes eight stages of maturation for each tooth sequenced with capital letters from $\mathrm{A}$ to $\mathrm{H}$, where each stage becomes a numerical value, which when added gives us an amount corresponding to the degree of maturity for the particular subject (this alphabetical description of the stages of dental maturation are converted into constant numerical values to be correlated by gender). Generally, only the left mandibular side is evaluated (no 


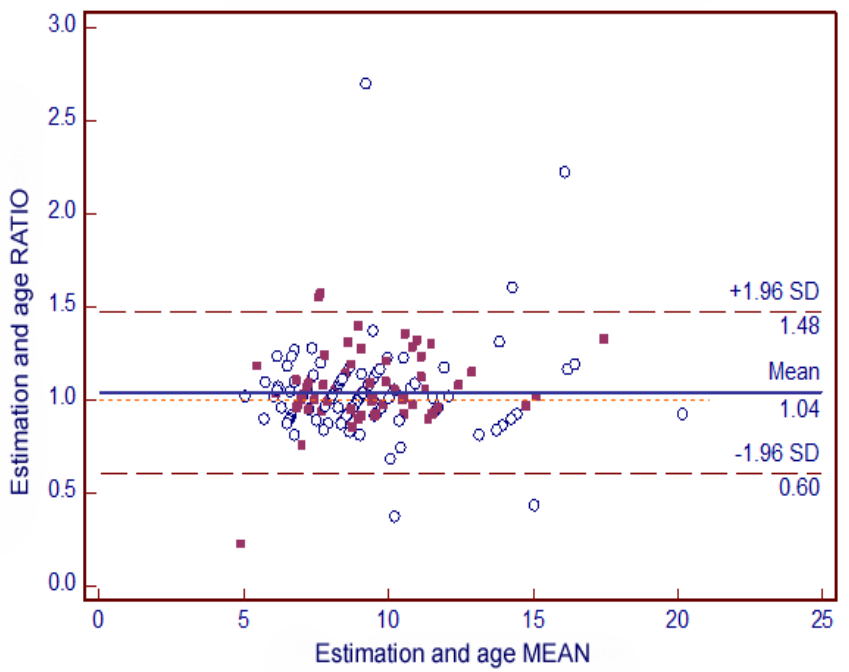

Graphic 5. Agreement between the Ubelaker method and chronological age (Males: squares, Females: circles)

differences were found between both sides) because observation of the maxillary teeth is more difficult due to overlapping of osseous structures, especially during the (first) six years of life ${ }^{16}$. The method was designed to be used within the clinical dentistry context for the purpose of determining the degree of dental development and within the forensic context to estimate chronological age from the degree of dental maturation ${ }^{8}$.

However, Smith ${ }^{16}$ manifested that it is ideal for determining the stage of dental maturation in individuals with known chronological age, but not as a method for predicting chronological age. In fact, Maber et al. ${ }^{12}$ found that this method was the most precise in estimating age for forensic purposes, even when the individual's gender was unknown, in addition to being an easily applied numerical and comparative method, given the representation it makes of each one of the development stages of the teeth.

Demirjian and Levesque ${ }^{18}$, studied dental development through 5,437 panoramic radiographs (2,705 girls and 2,732 boys) in a French-Canadian population ranging between 2.5 and 19 years of age. The authors reportedly found differences between men and women in the highest age ranges, in which the women had a more advanced dental development than the men. In the lower ranges, sexual dimorphism was not observed. Reventlid et al. ${ }^{19}$, applied the method by Demirjian, Goldstein and Tanner along with other methods in 197

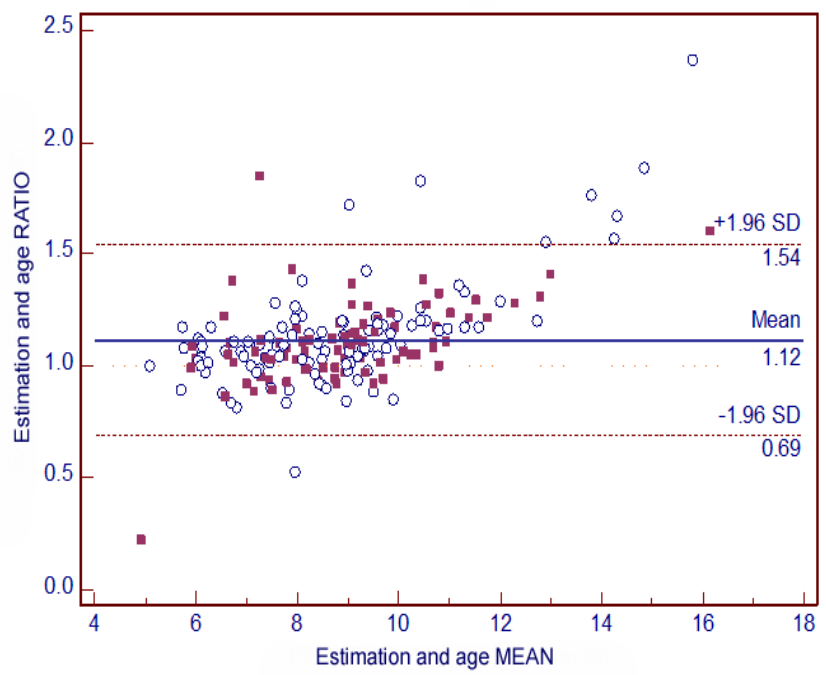

\section{Graphic 6. Agreement between the Smith method and chronological age (Males: squares, Females: circles)}

radiographs of children $5,6,9$, and 12 years of age, concluding that any method is acceptable when approximating the chronological age with respect to the dental age. Similarly, Rai and Anand ${ }^{20}$ found high precision with this method when used with small children. For Latin America, Loevy ${ }^{22}$ found that dental development of African American and Latin American children is more advanced with respect to the chronological age proposed in the method by Demirjian, Goldstein and Tanner.Likewise, this author manifests that said method is very reliable and results ideal in estimating dental age because it is based on the development of tooth germs, which is not affected by environmental factors.

Already in Colombia, Arévalo and Infante ${ }^{3}$ conducted a study with a sample of 61 panoramic radiographs belonging to a sampling of Colombians classified into three age groups: 8 to 9 years, 10 to 11 years, and 12 to 13 years, which compared four dental age estimation methods (Nolla, Moorrees, Fanning and Hunt, Demirjian, Goldstein and Tanner, and Smith) in which the method by Moorrees, Fanning and Hunt and the method by Smith were the most exact.

This variability in the results of the different reports is explained by PDavis and Hagg ${ }^{22}$, who concluded that the method by Demirjian, Goldstein and Tanner is not applicable to all populations because of the ethnic differences.

In this study, the Demirjian, Goldstein and Tanner 
method presented a high correlation coefficient between dental age and radiographic age (Table 1); nevertheless, the method tended to underestimate (Graphic 4).

Ubelaker (1989). In 1989, Ubelaker developed a graphic method that represents formation stages of the crowns and roots of temporary and permanent teeth and the eruption sequence of a group of Native Americans. Rodríguez ${ }^{1}$ indicates that this method is specific for Amerindian populations.

González-Colmenares et al. ${ }^{23}$, carried out a study comparing two methods, including the one by Ubelaker, for estimating age in a population of 79 Colombian Caucasoid Mestizos, in which they conclude that it is necessary to create specific formulas to estimate age in each human group.

Smith ${ }^{24}$ made a comparison of the degree of precision between the graphic comparative methods by Schour and Massler and by Ubelaker in 419 Caucasian American children between 5 and 15 years of age, concluding that both methods have low correlation levels between dental age and chronological age with a tendency for overestimation. In this study, as in the other methods examined, the Ubelaker method presented a high correlation coefficient with a tendency for overestimating the chronological age (Table 1, Graphic 5).

Smith (1991). In 1991, Smith modified the method by Moorrees, Fanning and Hunt, describing each tooth individually and averaging all the ages, in such a manner that the median corresponded to the dental age. Note that in this method, the apical closure does not have a value assigned as a marker of dental age. What is interesting about this method is that it was focused specifically as an age prediction tool ${ }^{7}$. This numerical method has elevated and very significant approximation values; it is also easy to use, given that its main objective is age prediction ${ }^{4}$.

In 2002, Hernández and Sierra ${ }^{4}$ suggested that the Smith method is best suited for age estimation for Colombian individuals. In this study, the Smith method presented a rather high correlation coefficient (Table 1), quite similar to the method by Moorrees, Fanning and Hunt.

\section{CONCLUSIONS}

According to the correlation coefficients obtained in this study, all the methods may be used for estimating chronological age based on dental development. However, the method by Moorrees, Fanning and Hunt and the method by Smith (numerical methods) presented the greatest correlation between dental age and chronological age; while, the method by Logan and Kronfeld (comparative method) presented the lowest correlation.

If the correlation coefficient is expressed in terms of overestimation or underestimation of chronological age from the dental age, no significant discrepancy is observed, given that the different methods have standard deviations that increase as the individual's age increases. In fact, it can be seen in literature that the methods work best with temporary dentition and with early and late mixed dentition than with permanent dentition.

In the sample studied, the development of the teeth does not evidence sexual dimorphism.

With respect to bilateralism, dental development on the right and left sides presents high correlation between these with respect to chronological age. Generally, the methods used in this study only employ one side to observe dental development and eruption; however, we sought to observe bilateralism to determine if the teeth in each hemifacial had the same simultaneous development pattern, which was positively corroborated.

\section{RECOMMENDATIONS}

According to literature reports, there is sufficient information evidencing that the methods employed in estimating age from dental development vary in terms of underestimation or overestimation of age among different human groups. Hence, and given the ethnic diversity of the Colombian population, studies should be conducted involving the groups that predominantly make up the Colombian population (Andean Mestizos, Caribbean Mestizos, Afro-Colombians, and Indigenous groups), to generate new knowledge applicable to forensic sciences (age estimation within the basic identification quatrain) and dental anthropology (biological information of past populations based on dental development).

Likewise, it is important to conduct studies correlating different methods for age estimation, like physical methods (pubic and underarm hair and development of secondary sexual characters) and osseous methods (clavicle, ribs, and carpogram), to determine the versatility 
of the methods (cost, time, expertise), as well as accuracy levels (concordance).

Given that age estimation methods stemming from the eruption and development of the teeth function best in children, it is very convenient to conduct a study with a broad sample, which implies the analysis of the development and eruption of the third molars for young adults.

Conflict of interest. None of the authors has conflicts of interest related to this study.

\section{ACKNOWLEDGMENTS}

The authors thank the Vice Rectory of Research at Universidad del Valle for funding this project through the Internal Call for Projects for the Conformation of the 2008-2009 Research Projects Base.

\section{REFERENCES}

1. Rodríguez JV. La antropología forense en la identificación humana. Santa Fe de Bogotá: Universidad Nacional de Colombia; 2004.

2. Martín S. Estimación de la edad a través del estudio dentario. Ciencia Forense 2005; 7: 69-90.

3. Arévalo CM, Infante C. Análisis y comparación de cuatro métodos radiográficos para determinar la edad dental (maduración dental) en dientes permanentes. Inter J Dental Anthropol. 2001; 2: 9-15.

4. Hernández LF, Sierra LH. Análisis de estructuras dentales y óseas, determinantes de edades biológicas que permitan caracterizar tres grupos etáreos y tres edades cronológicas de importancia legal, en ambos géneros (tesis de pregrado). Santa Fe de Bogotá; Universidad Nacional de Colombia, Facultad de Odontología; 2002. p. 1-145.

5. Orjuela CE, Duque MA, Velosa G, Carreño MI, Constantín AE. Guía práctica para el dictamen odontológico forense y de dictamen de edad. Santa Fe de Bogotá: Instituto Nacional de Medicina Legal y Ciencias Forenses; 2004. p. 1-71.

6. Demirjian A, Goldstein H, Tanner JM. A new system of dental age assessment. Ann Hum Biol. 1973; 45: 211-27.

7. Bolaños MV, Manrique MC, Bolaños MJ, Briones MT. Approaches to chronological age assessment based on dental calcification. Forensic Sci Int. 2000; 110: 97-106.

8. Mourelle ML. Correlación entre la maduración dentaria e indicadores de crecimiento esquelético en pacientes odontopediátricos (tesis de doctorado). Madrid: Universidad Complutense, Facultad de Odontología; 2004. p. 1-154.

9. Maples WR. Forensic anthropology. In: Forensic dentistry. Stimson PC, Mertz CA, (eds.). New York: CRC Press; 1997.

10. Moreno S, León ME, Marín L, Moreno F. Comportamiento de los tejidos dentales y de algunos materiales de obturación dental sometidos a altas temperaturas con fines forenses. Colomb Med. 2008; 39 (Supl 1): 28-46.

11. Reppien K, Sejrsen B, Lynnerup N. Evaluation of postmortem estimated dental age versus real age: a retrospective 21year survey. Forensic Sci Int. 2006; 159: 84-8.

12. Maber M, Liversidge HM, Hector MP. Accuracy of age estimation of radiographic methods using developing teeth. Forensic Sci Int. 2006; 159: 68-73.

13. Logan WHG, Kronfeld R. Development of the human jaws and surrounding structures from birth to the age of fifteen years. JADA. 1933; 20: 379-427.

14. Schour I, Massler M. The development of the human dentition. JADA. 1941; 28: 1153-60.

15. Liversidge HM. Accuracy of age estimation from developing teeth of a population of known age (0-5.4 years). Int $J$ Osteoarchaeol. 2005; 4: 37-45.

16. Moorees CFA, Fanning EA, HuntEE. Age variation of formation stages for ten permanent teeth. J Dent Res. 1963; 42: 264-73.

17. Smith BH. Standards of human tooth formatyion and dental age assesment. In: Advances in dental anthropology. Kelley MA, Spencer C (eds.). New York: Wiley-Liss Inc; 1991. p. 143-68.

18. Demirjian A, Levesque GY. Sexual differences in dental development and prediction of emergence. J Dent Res. 1980; 59: 1110-22.

19. Reventlid M, Mornstad H, Teivens AA. Intra- and interexaminer variations in four dental methods for age estimation of children. Swed Dent J. 1996; 20: 133-9.

20. Rai B, Anand SC. Tooth developments: an accuracy of age estimation of radiographic methods. World J Med Sci. 2006; 1: 130-2.

21. Loevy HT. Maturation of permanent teeth in Black and Latino children. Acta Odontol Pediatr. 1983; 4: 59-62.

22. Davis PJ, Hagg U. The accuracy and precision of the Demirjian system when used for age determination in Chinese children. Swed Dent J. 1994, 18: 113-6.

23. González-Colmenares G, Botella-López MC, Moreno-Rueda G, Fernández-Cardenete JR. Age estimation by a dental method: Acomparison of Lamendin's and Prince \& Ubelaker's Technique. J Forensic Sci. 2007; 52: 1156-60.

24. Smith EL. A test of Ubelaker's method of estimating subadult age from the dentition. (Degree Master in Human Biology). Indianapolis: University of Indianapolis; 2005. p. 1-72. 